AARP

\section{Pandemic impact on a healthy lifestyle among LGBTQ+ adults ages 50+}

Six in ten (59\%) of LGBTQ+ adults ages 50+ agree (completely or somewhat) that their health felt out of control last year.

\section{LGBTQ Health has felt out of control in the last year}
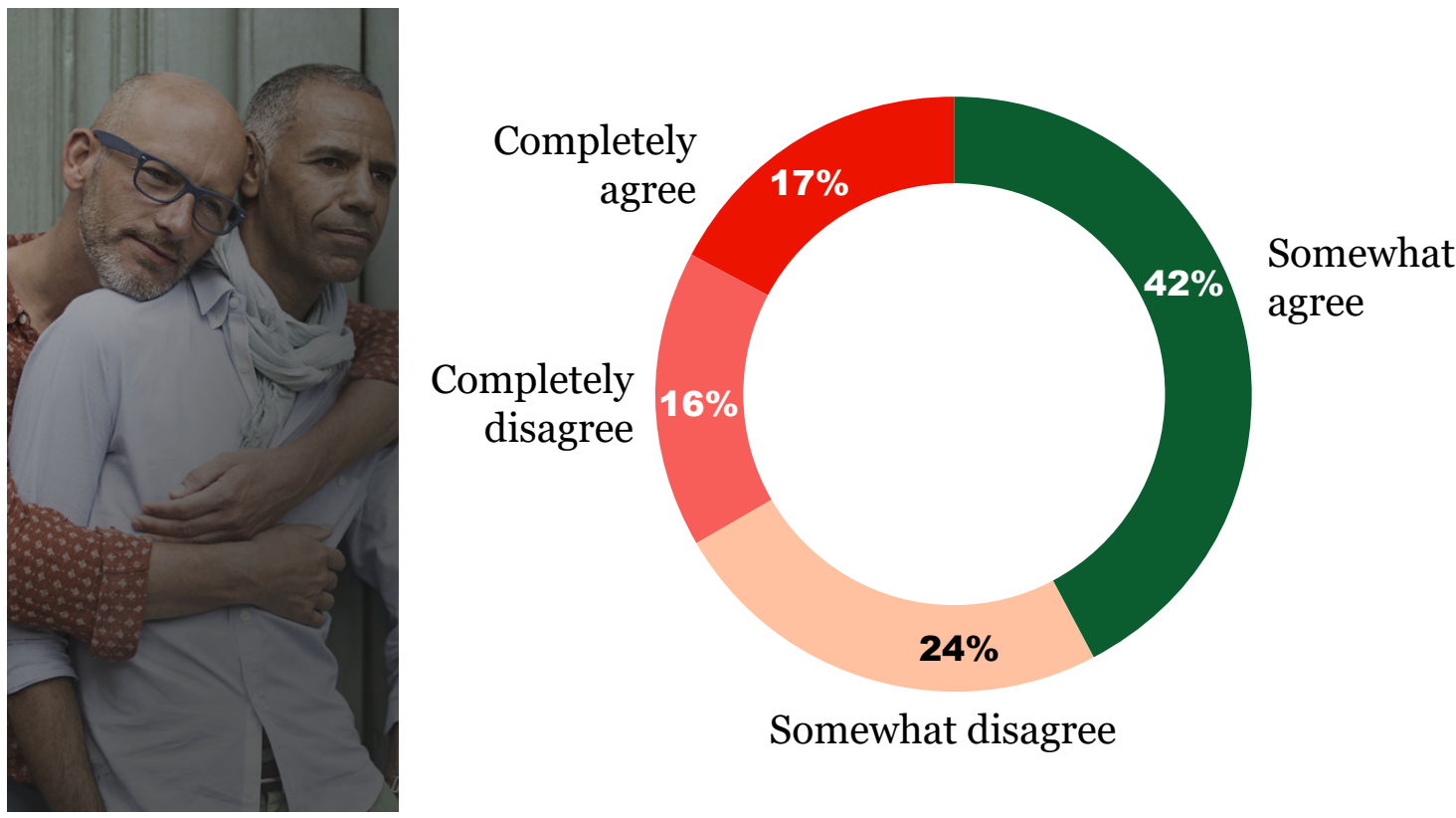

Somewhat disagree

Source: 2021 AARP Healthy Living Survey @2021 AARP ALL RIGHTS RESERVED

Contacts: Cheryl L. Lampkin | clampkin@aarp.org

Media inquiries: media@aarp.org. https://doi.org/10.26419/res.00487.012
Nearly half (47\%) of LGBTQ+ adults ages 50+ say it has been harder to maintain a healthy lifestyle in the last year. However, two-thirds (68\%) intend to make improvements to their health by getting regular exercise and nearly half (44\%) are again engaging in social activities by visiting with family and friends.

\section{Maintaining a healthy lifestyle}
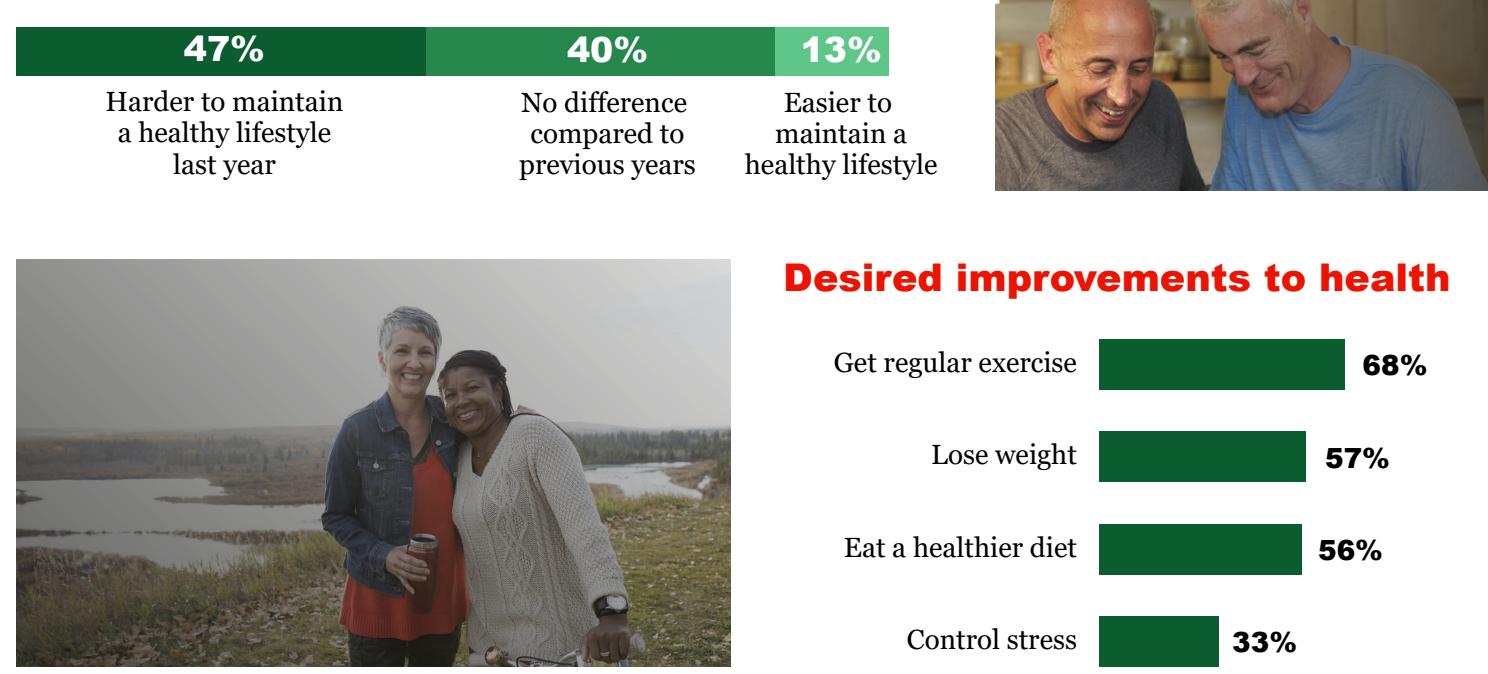

Desired improvements to health

Get regular exercise

Lose weight

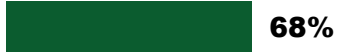

Eat a healthier diet

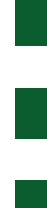
$57 \%$

Control stress $56 \%$

\section{Current activities}

$$
\begin{aligned}
& \text { Visit family/friends } \\
& \text { Hug an acquaintance }
\end{aligned}
$$

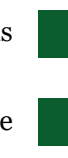
$44 \%$

Host/attend a small gathering

$$
\text { Stay in a hotel }
$$

$$
\text { l }
$$

Shake a stranger's hand
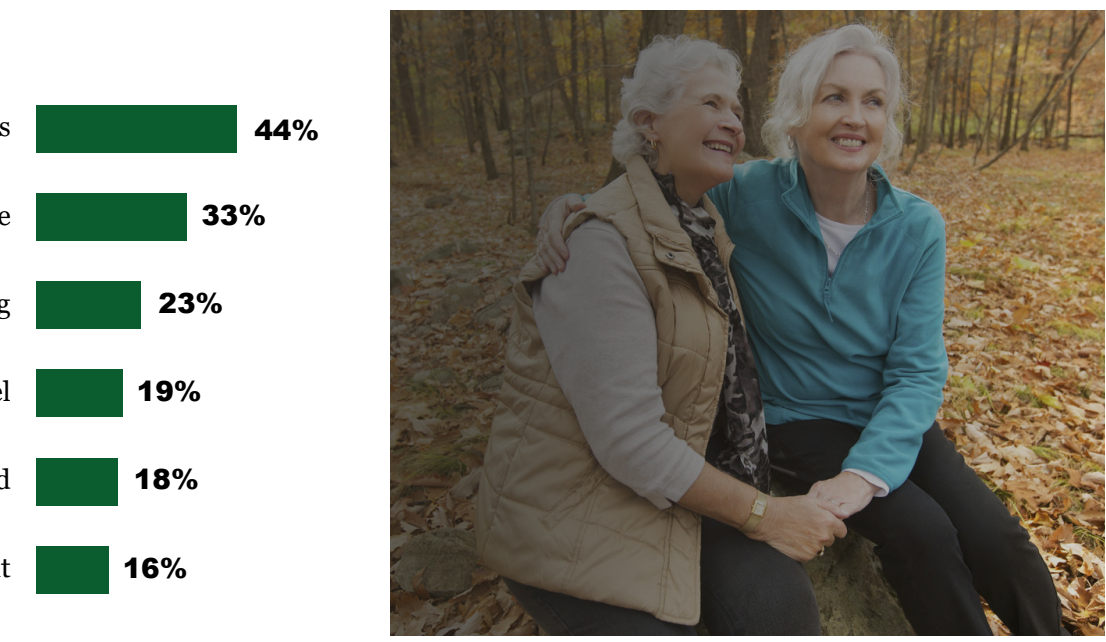